\title{
Methodology for Determining the Optimal Values of Resistanceat the Ends of the Jointless Track Circuit with Considering TwofoldShunting
}

\author{
Ravshan Aliev', Marat Aliev ${ }^{2}$, Ezozbek Tokhirov ${ }^{3}$ \\ ${ }^{1}$ Tashkent State Transport University, Tashkent, Uzbekistan, silara@mail.ru \\ ${ }^{2}$ Tashkent State Transport University, Tashkent, Uzbekistan \\ ${ }^{3}$ Tashkent State Transport University, Tashkent, Uzbekistan, etokhirov@yahoo.com
}

\begin{abstract}
The main criterion for the functioning of jointless rail circuits with a current receiver is to ensure the reliability of their work and ensure the safety of train traffic. In jointless rail circuits with current information retrieval when two trains are on the relay end, a critical situation may arise when the track receiver can trigger from the second train when the first train is on the controlled section. To determine the critical distance and optimal values at the ends of the rail circuit, the article presents equivalent circuits and derives the shunt sensitivity equations, determines the critical distance of the minimum shunt sensitivity and the equation for determining the optimal resistances at the ends of a jointless rail circuit with a current receiver.
\end{abstract}

Key words: tonal track circuits; track receiver; substitution schemes, input resistances, quadrupole coefficients, receiver current, transmission resistance, shunt sensitivity.

\section{INTRODUCTION}

Investigations of track circuits [7] can be performed under operating conditions - linear investigations, on laboratory mock-ups - laboratory investigations using a computer. The most effective research method is a computer method [11]. It allows you to conduct a comprehensive analysis of the track circuit, identify adverse conditions, optimize the method of monitoring the state of the rail line. To carry out such studies, a mathematical model of the rail line [8], [17] should be compiled, which would make it possible to establish the relationship between currents and voltages at the ends of the rail line for various parameters of the rail line and input resistances at the ends. The final stage of the study is a comparative analysis of the calculation results and linear tests.

Known substitutionscheme [3], [4], [8], [15] of the rail line allow you to analyze the operation of the TC with the receiver, which has a fixed value of switching voltages. For each of the main operating modes, the most unfavorable values (from the point of view of performing these modes) of insulation resistance $r_{i}$, voltage of the power supply $U_{p s}$, coordinates of the location of the train (shunt) $X_{s h}$, and damage to the rail line $X_{\mathrm{c}}$ were taken as the calculated ones. If, under the most adverse conditions, reliable control of the state of the rail line is achieved, then, under other conditions, it will also be performed.

\section{METHODS}

In jointlesstrack circuits with current removal, the possible range of resistance changes at the ends of the track circuit is of great interest, in which the shunt and control modes are provided taking into account the specific features of the operation of jointlesstrack circuits.

When calculating the optimal values of the resistance at the ends and the maximum lengths in jointlesstrack circuits with current removal [9] from the condition of the shunt mode, it is necessary to take into account the presence of the second train on the adjacent track circuit $\mathrm{R}_{\text {sh1 }}$ (Figure 2 ), and in normal operation, the presence of the outgoing train from the supply end of the track circuitR $\mathrm{sh}_{\mathrm{sh}}($ Figure 1$)$. 


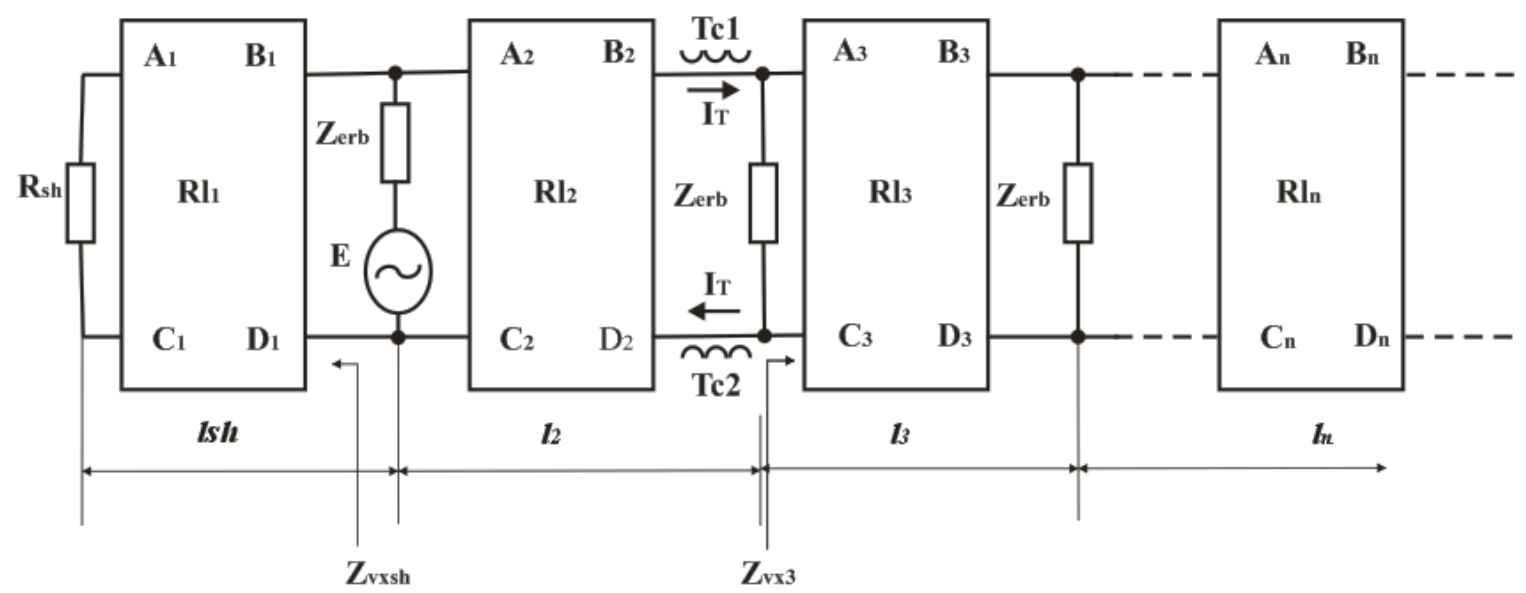

Figure 1:Substitution schemeof a continuous rail circuit with a current receiver in normal mode

In this scheme:

$l_{2}$ isinvestigated the track circuit length;

lsh isdistance to the outgoing train;

$\mathrm{RL}_{1}, \mathrm{RL}_{2}, \mathrm{RL}_{3} \ldots \ldots . \mathrm{RLnarequadripolestrack}$ circuits;

$\mathrm{R}_{\mathrm{sh}}$ isoutgoing train resistance;

$\mathrm{Z}_{\mathrm{ebr}}$ isreverse input resistance of the supply end of the track circuit;

$\mathrm{Tc} 1$ and Tc2 are receiving coils;

$\mathrm{Z}_{\mathrm{vxsh}}$ is input resistance of the adjacent track circuitfrom the side of the outgoing train:

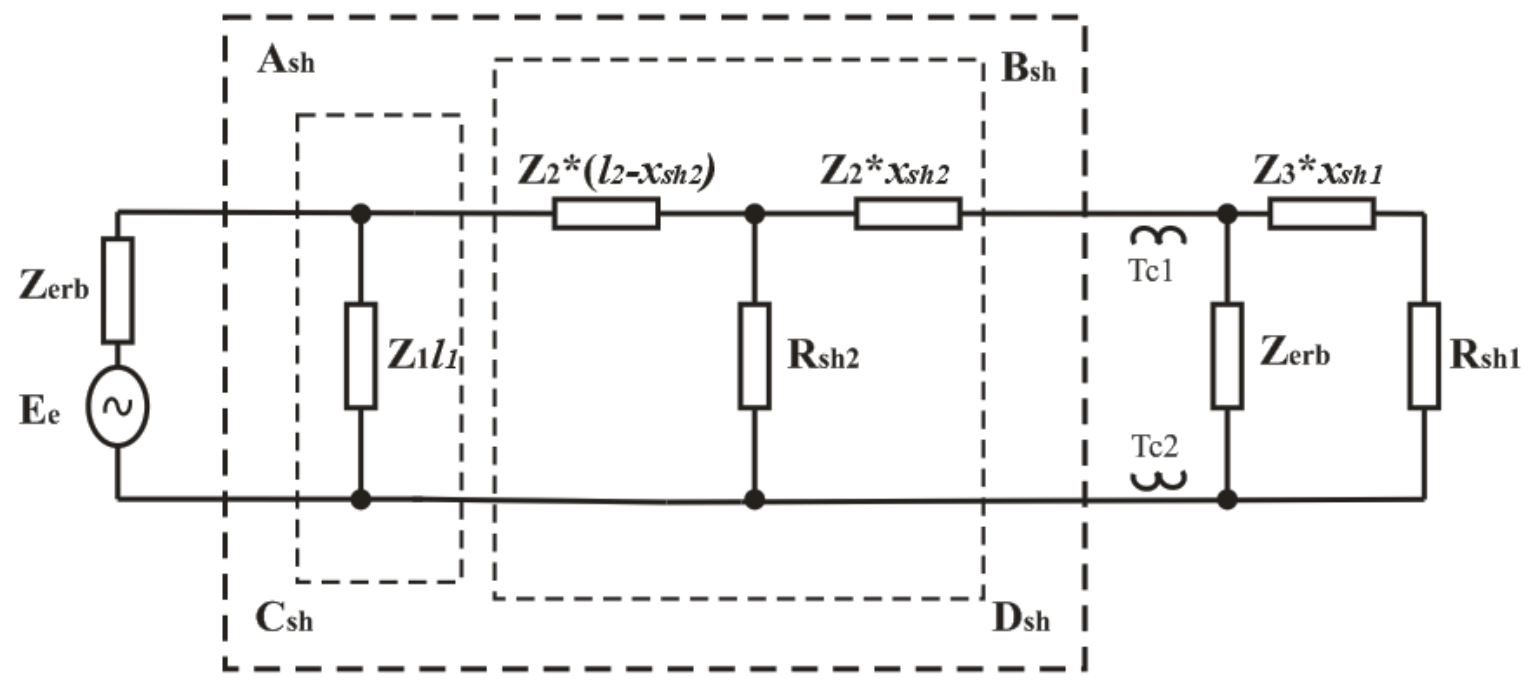

Figure 2: Shuntlesstrack circuitsubstitution schemewith current receiver

In this scheme:

$\mathrm{R}_{\mathrm{sh} 2}$ is resistance of the train shunt, the train entered the controlled area;

$\mathrm{R}_{\mathrm{sh} 1}$ is resistance of a train shunt, a train located on an adjacent rail circuit;

$\mathrm{z}_{1}$ is the resistance of the rail loop of the section where the retreating train is located;

$l_{1}$ is the distance to the receding train;

$\mathrm{X}_{\mathrm{sh} 2}$ is distance from the relay end to the train located in the controlled area;

$\mathrm{X}_{\mathrm{sh} 1}$ is distance from the relay end to the train located on the adjacent rail chain;
Given these features for the shunt mode, the equation of the shunt sensitivity Rsh2 can be represented as follows:

$$
\begin{aligned}
R_{s h 2} & =\frac{Z_{e b r} * z_{2} * x_{2}+z_{2}^{2} *\left(l_{2}-x_{s h 2}\right) *}{N \frac{z_{v}}{z_{v}+Z_{e b r}}\left[A_{n} * Z_{e b r}+B_{n}+Z_{e b r} *\left(C_{n} * Z_{e b r}+D_{n}\right)\right]-} \rightarrow \\
& \rightarrow \frac{\rightarrow * x_{s h 2} *\left(1+\frac{Z_{e b r}}{Z_{e b r}+z_{2} l_{2}}\right)}{-\left[\left(1+\frac{Z_{e b r}}{Z_{e b r}+z_{2} l_{2}}\right) * Z_{2} l_{2}+2 Z_{e b r}\right]} .(1)
\end{aligned}
$$

where

$$
\begin{gathered}
A_{n}=\operatorname{ch} \gamma_{2} l_{2}+\frac{z_{v 2} * \operatorname{sh} \gamma_{2} l_{2}}{Z_{v x 3}} \\
B_{n}=z_{v 2} * \operatorname{sh} \gamma_{2} l_{2}
\end{gathered}
$$


Ravshan Aliev et al., International Journal of Emerging Trends in Engineering Research, 8(9), September 2020,5048 - 5052

$$
\begin{gathered}
C_{n}=\frac{c h \gamma_{2} l_{2}}{Z_{v x s h}}+\frac{1}{Z_{v 2}}+\frac{1}{Z_{v x 3}} *\left(\frac{Z_{v 2} * \operatorname{sh} \gamma_{2} l_{2}}{Z_{v x s h}}+\operatorname{ch} \gamma_{2} l_{2}\right) ; \\
D_{n}=\frac{z_{v 2} * s h \gamma_{2} l_{2}}{Z_{v x s h}}+\operatorname{ch} \gamma_{2} l_{2},
\end{gathered}
$$

arecoefficients rail quadripole controlled section in normal mode.

In equation (1), the value of $X$ is determined from the condition of ensuring reliable shunting when the two trains approach each other at the relay end of the track circuitaccording to the equation.:

where

$$
X^{4}+X^{3} M_{3}+X^{2} M_{2}+X M_{1}+M_{0}=0
$$

$$
\begin{gathered}
M_{0}=\frac{P_{0}^{2}-Z_{2}^{2}}{P_{2}^{2}} \\
M_{1}=\frac{2 P_{0} P_{1} \cos \left(\varphi_{1}-\varphi_{0}\right)}{P_{2}^{2}} \\
M_{2}=\frac{P_{1}^{2}+2 P_{0} P_{2} \cos \left(\varphi_{2}-\varphi_{0}\right)}{P_{2}^{2}} ; \\
M_{3}=\frac{2 P_{1} P_{2} \cos \left(\varphi_{2}-\varphi_{1}\right)}{P_{2}^{2}} ; \\
P_{0}=-\left[z_{2} l_{2}\left(1+\frac{Z_{e b r}}{Z_{e b r}+z_{2} l_{2}}\right)+Z_{e b r}\right] ; \\
P_{1}=-\left[\frac{Z_{e b r}}{R_{s h 2}}+\frac{Z^{2} l\left(2 Z_{e b r}+Z l\right)}{\left(Z_{e b r}+z_{2} l_{2}\right) R_{s h 2}} ;\right. \\
P_{2}=-\frac{z_{2}^{2}\left(2 Z_{e b r}+z_{2} l_{2}\right)}{\left(Z_{e b r}+z_{2} l_{2}\right) R_{s h 2}} .
\end{gathered}
$$

Based on the found values of $\mathrm{X}$, its optimal value is selected and substituted in equation (1).

Resistance modules $Z_{e b r}$ corresponding to the given and maximum allowable lengths of track circuits are determined by the solution of equation (1).

Solving equation (1) with respect to $Z_{e b r}$ in complex form, we obtain:

$$
\begin{aligned}
& \mathrm{N} *\left[\mathrm{Z}_{\mathrm{ebr}}^{3} * \mathrm{C}_{\mathrm{n}} * \mathrm{Z}_{\mathrm{V}}+\mathrm{Z}_{\mathrm{ebr}}^{2} * \mathrm{Z}_{\mathrm{V}} *\right. \\
& *\left(\mathrm{~A}_{\mathrm{n}}+\mathrm{C}_{\mathrm{n}} * \mathrm{z}_{2} * \mathrm{l}_{2}+\mathrm{D}_{\mathrm{n}}\right)+ \\
& +\mathrm{Z}_{\mathrm{ebr}} * \mathrm{Z}_{\mathrm{v}}\left(\mathrm{A}_{\mathrm{n}} * \mathrm{Z}_{2} * \mathrm{l}_{2}+\mathrm{B}_{\mathrm{n}}+\mathrm{D}_{\mathrm{n}} * \mathrm{Z}_{2} * \mathrm{l}_{2}\right)+ \\
& \left.+\mathrm{B}_{\mathrm{n}} * \mathrm{Z}_{\mathrm{v}} * \mathrm{Z}_{2} * \mathrm{l}_{2}\right] \\
& =\mathrm{Z}_{\mathrm{ebr}}^{3} *\left(1+\frac{\mathrm{Z}_{2} * \mathrm{X}_{\mathrm{sh} 2}}{\mathrm{R}_{\mathrm{sh} 2}}\right)+\mathrm{Z}_{\mathrm{ebr}}^{2}\left[\mathrm{Z}_{\mathrm{v}}\left(1+\frac{\mathrm{Z}_{2} * \mathrm{X}_{\mathrm{sh} 2}}{\mathrm{R}_{\mathrm{sh} 2}}\right)+\right. \\
& \left.+\frac{2 \mathrm{z}_{2}^{2} * \mathrm{x}_{\mathrm{sh} 2}\left(\mathrm{l}_{2}-\mathrm{x}_{\mathrm{sh} 2}\right)}{\mathrm{R}_{\mathrm{sh} 2}}+\frac{\mathrm{z}_{2}^{2} * \mathrm{x}_{\mathrm{sh} 2} * \mathrm{l}_{2}}{\mathrm{R}_{\mathrm{sh} 2}}+3 \mathrm{z}_{2} * \mathrm{l}_{2}\right]+ \\
& +\mathrm{Z}_{\mathrm{ebr}}\left\{\mathrm{Z}_{\mathrm{v}}\left[\frac{2 \mathrm{z}_{2}^{2} * \mathrm{x}_{2}\left(\mathrm{l}_{2}-\mathrm{x}_{\mathrm{sh} 2}\right)}{\mathrm{R}_{\mathrm{sh} 2}}+\frac{\mathrm{z}_{2}^{2} * \mathrm{x}_{\mathrm{sh} 2} * \mathrm{l}_{2}}{\mathrm{R}_{\mathrm{sh} 2}}+3 \mathrm{z}_{2} * \mathrm{l}_{2}\right]+\right. \\
& \left.+z_{2}^{2} l_{2}^{2}+\frac{z_{2}^{3} * x_{2}\left(l_{2}-x_{s h 2}\right)}{R_{s h 2}}\right\}+Z_{v}\left[z_{2}^{2} l_{2}^{2}+\right. \\
& \left.+\frac{z_{2}^{3} * x_{s h 2}\left(l_{2}-x_{s h 2}\right)}{R_{s h 2}}\right] .
\end{aligned}
$$

Denoteinequation (2)

$$
\begin{gathered}
C_{n} Z_{v}=P_{1} \\
Z_{e b r}^{2} * Z_{v} *\left(A_{n}+C_{n} * Z_{2} * l_{2}+D_{n}\right)=P_{2} \\
Z_{v}\left(A_{n} * Z_{2} * l_{2}+B_{n}+D_{n} * Z_{2} * l_{2}\right)=P_{3}
\end{gathered}
$$

$$
\begin{gathered}
Z_{v} * B_{n} * z_{2} * l_{2}=P_{4} ; \\
1+\frac{x_{s h 2}}{R_{s h 2}}=P_{5} ; \\
Z_{v}\left(1+\frac{x_{s h 2}}{R_{s h 2}}\right)+\frac{z_{2}^{2} * x_{s h 2} * l_{2}}{R_{s h 2}}+\frac{z_{2}^{2} * x_{s h 2} * l_{2}}{R_{s h 2}}+3 z_{2} * l_{2}=P_{6} ; \\
Z_{v}\left[\frac{2 z_{2}^{2} * x_{2}\left(l_{2}-x_{s h 2}\right)}{R_{s h 2}}+\frac{z_{2}^{2} * x_{s h 2} * l_{2}}{R_{s h 2}}+3 z_{2} * l_{2}\right]+ \\
+z_{2}^{2} l_{2}^{2}+\frac{z_{2}^{3} * x_{2}\left(l_{2}-x_{s h 2}\right)}{R_{s h 2}}=P_{7} ; \\
Z_{v}\left[z_{2}^{2} l_{2}^{2}+\frac{z_{2}^{3} * x_{s h 2}\left(l_{2}-x_{s h 2}\right)}{R_{s h 2}}=P_{8} .\right.
\end{gathered}
$$

After replacing, we get:

$$
\begin{gathered}
N\left(Z_{e b r}^{3} P_{1}+Z_{e b r}^{2} P_{2}+Z_{e b r} P_{3}+P_{4}\right)=Z_{e b r}^{3} P_{5}+Z_{e b r}^{2} P_{6}+ \\
+Z_{e b r} P_{7}+P_{8} .
\end{gathered}
$$

To exclude the argument $\varphi_{N}$, we equate the squares of the modules of the right and left sides of equation (3) and after the transformation, we obtain:

$$
Z_{e b r}^{6}+Z_{e b r}^{5} M_{5}+Z_{e b r}^{4} M_{4}+Z_{e b r}^{3} M_{3}+Z_{e b r}^{2} M_{2}+Z_{e b r} M_{1}+M_{0}=0 .
$$

The values $M_{5}, M_{4}, M_{3}, M_{2}, M_{1}, M_{0}$ are real, defined by the following equations:

$$
\begin{gathered}
M_{0}=\frac{N^{2} P_{4}^{2}-P_{8}^{2}}{N^{2} P_{1}^{2}-P_{5}^{2}} ; \\
M_{1}=\frac{2 N^{2} P_{2} P_{4} \cos \left(\varphi_{3}+\varphi_{e b r}-\varphi_{4}\right)-2 P_{7} P_{8} \cos \left(\varphi_{7}+\varphi_{e b r}-\varphi_{8}\right)}{N^{2} P_{1}^{2}-P_{5}^{2}} ;
\end{gathered}
$$

$$
\begin{gathered}
M_{2}=\frac{2 N^{2} P_{2} P_{4} \cos \left(\varphi_{2}+2 \varphi_{e b r}-\varphi_{4}\right)-2 P_{6} P_{8} \cos \left(\varphi_{6}+2 \varphi_{e b r}-\varphi_{8}\right)}{N^{2} P_{1}^{2}-P_{5}^{2}} ; \\
M_{3}=\frac{2 N^{2}\left[P_{1} P_{4} \cos \left(\varphi_{1}+3 \varphi_{e b r}-\varphi_{4}\right)+P_{2} P_{3} \cos \left(\varphi_{2}+\varphi_{e b r}-\varphi_{3}\right)\right]-}{N^{2} P_{1}^{2}-P_{5}^{2}} \\
\frac{-2\left[P_{5} P_{8} \cos \left(\varphi_{5}+3 \varphi_{e b r}-\varphi_{6}\right)-P_{6} P_{7} \cos \left(\varphi_{6}+\varphi_{e b r}-\varphi_{7}\right)\right.}{N^{2} P_{1}^{2}-P_{5}^{2}} ; \\
M_{4}=\frac{2 N^{2} P_{4} P_{3} \cos \left(\varphi_{1}+2 \varphi_{e b r}-\varphi_{3}\right)+N^{2} P_{2}^{2}-P_{6}^{2}-}{N^{2} P_{1}^{2}-P_{5}^{2}} \\
\frac{-2 P_{5} P_{7} \cos \left(\varphi_{5}+2 \varphi_{e b r}-\varphi_{7}\right)}{N^{2} P_{1}^{2}-P_{5}^{2}} ; \\
M_{5}=\frac{2\left[N^{2} P_{4} P_{3} \cos \left(\varphi_{1}+\varphi_{e b r}-\varphi_{2}\right)-P_{5} P_{6} \cos \left(\varphi_{5}+\varphi_{e b r}-\varphi_{6}\right)\right]}{N^{2} P_{1}^{2}-P_{5}^{2}}
\end{gathered}
$$

The equation of the sixth degree with real coefficients is solved by the method of partial values or on a computer.

\section{RESULTAND DISCUSSIONS}

The substitution schemes presented of the jointless track circuit with current receiver, the equations of the shunt sensitivity and the critical location of the minimum value of the shunt sensitivity are derived. The equations for determining the optimal resistance values at the ends of the track circuit are derived.Comparative analyzes of track circuits with current and potential receiver are given.

Using the above formulas, an algorithm was developed and calculations were carried out to determine the optimal 
resistances at the ends of the control sensors in comparison with the known control sensors with potential receivers. The calculations were carried out for the signal current frequency $\mathrm{f}=475 \mathrm{~Hz}$, insulation resistance $\mathrm{r} i=1 \mathrm{Ohm} *$ $\mathrm{km}$ and different resistance arguments at the ends of the control sensors, the calculation results are shown in Table 1 , bywhich shows that the resistances at the ends of the control sensors with a current receiver different from the resistances at the ends for control sensors with a potential receiver.

Table 1: Optimal resistances at the ends of control sensors with current receivers in comparison with known control sensors with potential receivers at $\mathbf{f}=\mathbf{4 7 5} \mathbf{~ H z}$,

\begin{tabular}{|c|c|c|c|}
\hline $\begin{array}{c}\text { L-rail } \\
\text { line } \\
\text { length, } \\
\text { km }\end{array}$ & $\begin{array}{c}Z_{\text {ebr }} \text { is } \\
\text { current } \\
\text { track } \\
\text { receiver,Om }\end{array}$ & $\begin{array}{c}Z_{\text {ebr }} \text { is } \\
\text { with potential } \\
\text { receiver,OM }\end{array}$ & $\begin{array}{c}\text { difference } \\
\text { in } \%\end{array}$ \\
\hline 0,25 & 0,14 & 0,125 & 3,703703704 \\
\hline 0,45 & 0,15 & 0,137 & 2,040816327 \\
\hline 0,55 & 0,16 & 0,146 & 2,564102564 \\
\hline 0,75 & 0,17 & 0,157 & 1,796407186 \\
\hline 0,85 & 0,18 & 0,167 & 1,694915254 \\
\hline 0,95 & 0,19 & 0,175 & 2,702702703 \\
\hline 1,05 & 0,2 & 0,187 & 1,52284264 \\
\hline 1,15 & 0,22 & 0,193 & 3,286384977 \\
\hline 1,25 & 0,25 & 0,225 & 2,040816327 \\
\hline 1,35 & 0,28 & 0,244 & 2,189781022 \\
\hline 1,45 & 0,32 & 0,293 & 2,236421725 \\
\hline 1,45 & 0,37 & 0,32 & 1,648351648 \\
\hline 1,55 & 0,44 & 0,417 & 0,686498856 \\
\hline & & & \\
\hline
\end{tabular}

\section{CONCLUSION}

The proposed equations of the shunt sensitivity of a continuous track circuitwith a current receiver in the presence of two trains at the receiving end of the track circuit, by which it is possible to determine the critical value of the distance to the minimum value of the shunt sensitivity, as well as equations for determining the optimal resistance parameters at the ends of the track circuit, will allow research and selection optimum values of the resistances and the lengths at the ends of track circuits.

\section{REFERENCES}

1. M.M.Aliev, R.M. Aliev, AkbarovU. Track circuit apparatus without isolation circuits.Utility Model Patent. Intellectual Property Agency of the Republic of Uzbekistan. Tashkent. No FAP 01132 dated July 21, 2015.

2. R. M. Aliyev, M.M. AliyevIntelligent system of control of track circuits on high - speed lines. WCIS - 2016. 9 World Conference on Intelligent Systems for Industrial Automation. Tashkent, Uzbekistan, October pp. 25-27, 2016.

3. N. Aripov, R. Aliyev, D. Baratov, E. AmetovaFeatures of Construction of Systems of Railway Automatics and Telemechanics at the Organization of High-Speed Traffic in the Republic of UzbekistanProcedia Engineering 134(2016) pp. 175-180.

DOI: 10.1016/j.proeng.2016.01.057

4. Aliev R. M. Determination of the optimum parameters of jointless rail chains with a potential receiver. // Bulletin of TSTU. Tashkent, 2015. - No. 4. pp. $50-54$.

5. Arkatov, V. S. Rail chains of the main railways / V. S. Arkatov, A. I. Bazhenov, N. F. Kotlyarenko. - M.: Transport, 1992. -384 p.

6. Goncharov, K.V. Research of the digital track receiver of tonal rail chains / K.V. Goncharov // VisnikDnipropetr. nat. Un-tuzalizn. transp. im. Acad. V. Lazaryan. - D., VIP. 37, pp. 180-185, 2011

7. Goncharov, K.V. Correlation track receiver of tonal rail chains / K.V. Goncharov // VisnikDnipropetr. National University transp. im. Acad. V. Lazaryan. D., 2011.- VIP. 38. pp. 188-193.

8. Polevoy Y.I. Rail line models. Monograph / Polevoy Y.I; Russian Federation Federal University. Agency yellow. dor.Tr-that, Samarsk. state Univer. ways of communication. - Samara: SamGUPS, 2010.75 p.

9. Aliev R. M. Criteria for jointless rail circuits with a current track receiver. // Scientific works of the Republican scientific and technical conference "Resource-saving technologies in railway transport." Tashkentpp. 135-136, 2013

10. Vasilenko M.N., Denisov B.P., Kultin V., Rastegaev S.N. Calculation of parameters and operability testing of jointless tonal rail chains // Problems of transport systems. Izvestia PGUPS. No.2,pp. 101 109, 2006

11. Bezrodny B.F., Denisov B.R., Kultin V.B., Rastegaev S.N. Automation of calculation of parameters and verification of the mall. // Magazine "Automation, communication and informatics" No.1,pp. 15-17, 2010

12. GregorTheeg, Sergej VlasenkoRailway Signalling\& Interlocking. International Compendium. A DVV Media Group publication. Eurailpress,2009, 448 p.

13. W.Vantuono. Control systems trains in USA. International Raiway Journal No.10, pp. 32-34,36, 2009

14. K. V. Honcharov, Improving the stability of tonal track circuits under fluctuations of ballast resistance, Article (PDF Available) · January 2014,

DOI: $10.15802 /$ stp2013/19674 
15. Polevoy Y. I. Improvement of devices for monitoring the state of railway track sections. Samara: SamGAPS, 2005.p.133.

16. Aliev R. M. Criteria for jointless rail circuits with a current track receiver. // Scientific works of the Republican scientific and technical conference "Resource-saving technologies in railway transport." Tashkent,pp. 135-136, 2013

17. Aliev, R. M. \&Tokhirov, E. T. \&Aliev, M.M. (2020) The Mathematical Model of the Sensor for Monitoring the State of the Track Section with Current ReceiversIJRTE, Volume-8 Issue-5, January 2020, pp. 5634-5637.

DOI:10.35940/ijrte. E5936.018520. 